\title{
Insights into the Mechanisms of Fetal Growth Restriction-Induced Programming of Hypertension
}

\section{Benjamin Bhunu (D) \\ Isabel Riccio \\ Suttira Intapad (D)}

Department of Pharmacology, Tulane University School of Medicine, New

Orleans, LA, 70II2, USA
Correspondence: Suttira Intapad Department of Pharmacology, Tulane University School of Medicine, 1430

Tulane Avenue, \#8683, New Orleans, LA, 70II 2-2699, USA

Tel +l 504-988-9924

Email sintapad@tulane.edu

\begin{abstract}
In recent decades, both clinical and animal studies have shown that fetal growth restriction (FGR), caused by exposure to adverse uterine environments, is a risk factor for hypertension as well as for a variety of adult diseases. This observation has shaped and informed the now widely accepted theory of developmental origins of health and disease (DOHaD). There is a plethora of evidence supporting the association of FGR with increased risk of adult hypertension; however, the underlying mechanisms responsible for this correlation remain unclear. This review aims to explain the current advances in the field of fetal programming of hypertension and a brief narration of the underlying mechanisms that may link FGR to increased risk of adult hypertension. We explain the theory of DOHaD and then provide evidence from both clinical and basic science research which support the theory of fetal programming of adult hypertension. In addition, we have explored the underlying mechanisms that may link FGR to an increased risk of adult hypertension. These mechanisms include epigenetic changes, metabolic disorders, vascular dysfunction, neurohormonal impairment, and alterations in renal physiology and function. We further describe sex differences seen in the developmental origins of hypertension and provide insights into the opportunities and challenges present in this field.
\end{abstract}

Keywords: hypertension, FGR, placental insufficiency, LBW

\section{Introduction: The Concept of Fetal Programming of Adult Disease}

Recently, the theory of the developmental origins of health and disease (DOHaD), formerly known as the theory of fetal programming of adult disease, has gained traction as an important subject in both clinical and basic science medical research. ${ }^{1-5}$ Research suggests that pre- or postnatal exposure to developmental insults, such as nutrient insufficiency, and environmental exposures may result in temporary or permanent changes in fetal or neonate anatomy, epigenetics, metabolism, and physiology of the fetus or neonate and subsequent early onset of chronic diseases in life. ${ }^{1,3,6,7}$ David Barker et al were among the first groups to propose this idea with convincing epidemiological evidence linking low birth weight (LBW) to increased risk of morbidity and mortality from coronary heart disease as well as the development of insulin resistance and type II diabetes. ${ }^{8,9}$ Since publication of these landmark studies, several clinical and animal studies supported this idea, ${ }^{4,5,10,11}$ giving rise to the field of $\mathrm{DOHaD}$.

LBW is defined as an absolute birth weight of less than 2500 grams, and this condition is a clinical surrogate of a variety of distinct pregnancy-related 
complications, including fetal growth restriction (FGR), prematurity, and small for gestational age (SGA). ${ }^{12,13}$ Although LBW is closely associated with a high incidence of infant morbidity and mortality, the public health significance of this condition has risen in recent decades when it was discovered that poor adult health may be linked to compromised fetal growth. ${ }^{8,9,14}$ In most cases, LBW is a sign of poor fetal milieu during pregnancy and can be caused by multiple factors such as maternal and fetal genetics, presence of adverse environmental exposures, and placental insufficiency. ${ }^{12,14}$ Fetal growth restriction (FGR) is considered as a main cause of LBW. FGR results from insufficient uterine- placental perfusion, which leads to poor nutrient and oxygen supply to the fetus and consequently has detrimental outcomes on fetal growth and development and the diagnosis is based on the change in growth over time. ${ }^{15}$ In contrast, some babies experiencing prematurity, defined as birth before gestational week 37, have LBW and show signs of FGR. ${ }^{16}$ Note that not all premature babies are born with LBW. The recent statistic of the birth data in US for year 2019 reported $311,245(8.31 \%)$ babies born with LBW but the number of premature babies is even higher as 382,061 (10.23\%) babies born preterm. ${ }^{17}$ Furthermore, sometimes LBW babies are SGA. A child is regarded as SGA when their abdominal circumference or weight at birth is below the 10th percentile or two standard deviations of the average abdominal circumference or weight for that specific gestational age, race, and gender. ${ }^{18}$ Thus, infants in the category of SGA may or may not have growth restrictions.

Placental insufficiency is used to describe deficits in placental supply of oxygen and nutrients to the fetus, which becomes pathogenic by slowing fetal growth. ${ }^{19,20}$ FGR is mainly caused by placental insufficiency, elicited by a variety of factors including failure of uterine and placental spiral arteries to remodel, gestational hypertension, and maternal malnutrition. ${ }^{12,21-23}$ Suboptimal fetal nutrient supply and hypoxia may initiate preferential redistribution of blood to vital organs that are important for short-term survival such as the brain, myocardium and adrenal glands. ${ }^{12,13}$ However, organs that are important for the long-term survival such as the kidneys and liver may be deprived of sufficient blood supply and nourishment leading to compromised growth and subsequent organ dysfunction in adult life. ${ }^{24}$

Since FGR is now considered a risk factor for adult hypertension, ${ }^{25-27}$ we aim to give a synopsis of the current knowledge in the field of fetal programming of hypertension, with special attention to evidence from clinical and animal research. We further suggest possible underlying mechanisms, reasons for observed sex differences in this phenomenon, and conclude by discussing the challenges and opportunities available in this dynamic field.

\section{Fetal Programming of Hypertension: Evidence from Clinical and Preclinical Studies}

Genetics and lifestyle have been recognized as factors that promote hypertension development. However, several clinical studies now suggest that a suboptimal fetal environment can also initiate the progression of impaired blood pressure (BP) regulation. ${ }^{3,14,28,29}$ David Barker et al laid the foundation of the theory of fetal origins of health and diseases. ${ }^{9}$ In a cohort study of 22,846 adult men from the US, Curhan et $\mathrm{al}^{30}$ found that LBW was associated with increased incidence of hypertension whereas high birth weight was linked to increased incidence of diabetes mellitus. In contrast, both LBW and high birth weight increased systolic and diastolic BP in a study carried out on children and young adolescents in China. ${ }^{31}$ Several other studies support that LBW is directly associated with increased incidence of hypertension. ${ }^{26,28,32,33}$ Although children who suffered growth restriction may experience hypertension, ${ }^{27,34}$ the strength of association between LBW and essential hypertension becomes more pronounced in advanced age groups. ${ }^{35}$ These observations suggest that secondary insults accumulate with age and may shape and exacerbate hypertension in adult populations that experience fetal growth restriction. In a population-based cohort study on young Swedish men, both severity of birth weight restriction and the extent of prematurity increased the rise in BP. This underscores how the degree of FGR may be influential on increasing the risk of hypertension in adulthood. ${ }^{36}$ Human epidemiological research provides clear evidence that, to some extent, our fetal environment may determine the risk of developing hypertension in adult life.

Animal studies have advanced the field of fetal origins of health and diseases because they mitigate some of the confounding variable effects that influence the development of adult human diseases, such as genetic factors and postnatal environmental exposures. ${ }^{37}$ Many animal models of FGR have been developed including by various intervention to the pregnant dams such as the use of surgical 
methods to reduce blood flow to the placenta, ${ }^{19,38}$ immunological intervention, ${ }^{39}$ maternal protein restriction, ${ }^{40,41}$ and exposure to environmental agents such as drugs. ${ }^{42}$ Few genetically modified animal models in pregnant mouse and rat are also reported to develop spontaneous preeclampsia phenotype and produce FGR offspring. ${ }^{43,44}$ Although the causes of FGR may differ from one animal model to another, most investigations suggest that regardless of cause, suboptimal fetal environments are closely associated with adult risk for hypertension. ${ }^{11,40,42,45}$

\section{Potential Mechanisms Involved in Fetal Programming of Hypertension Epigenetics as a Driver of Fetal Programming of Hypertension}

Dynamic and inheritable modifications that change chromosome structure, but not gene sequence, are defined as epigenetics changes. These modifications regulate lineagespecific gene expression in several cellular processes including the pathogenesis of diseases and are a reflection of the interplay between DNA and environmental factors. ${ }^{25,46}$ Gene expression is partly dependent on the accessibility of genomic regions like promoters, enhancers, and silencers. These regions are essential for binding transcriptional factors such as activator and repressor proteins to DNA when they regulate gene transcription. ${ }^{47}$ Histone acetylation and methylation govern the accessibility of these genomic loci. In general, histone acetylation at lysine residues is associated with activation of gene expression while methylation may be associated with either transcriptional repression or activation, depending on gene specificity. Additional epigenetic modifications of histone proteins include sumoylation, ubiquitination, and phosphorylation. Methylation of DNA at specific cytosine regions of the promoter called $\mathrm{CpG}$ islands, is another form of epigenetic modification that regulates gene expression. Normally, promoter methylation is associated with transcriptional repression. ${ }^{4-50}$ Gene expression can also be regulated by non-coding RNAs; these small molecule expression profiles may correlate with the upregulation or suppression of specific genes. It should be noted that not all gene regulation mediated by non-coding RNAs fall under epigenetics. Epigenetic traits must be inheritable, ${ }^{51}$ which can be through mitosis and often encompasses the effects of maternal factors and early life experiences on long-term health. Epigenetic effects inherited through germline cells often manifest as paternal and transgenerational inheritance. ${ }^{52}$ Epigenetics regulate various cellular and physiological functions including embryonic development, genome imprinting during blastocyte maturation, and compensation of gene dosage during X-inactivation. ${ }^{46}$

In addition to altering the development of key organs that regulate BP homeostasis, poor fetal environment has been shown to induce epigenetic changes which might influence predisposition to adult hypertension and the transmission of this phenotype to subsequent generations. $^{7,25,53}$ Inhibition of DNA methyltransferase (DNMTs) with 5aza2DC and antagonism of histone deacetylase (HDAC) with valproic acid during the fetal life of rats exposed to dexamethasone, inhibited the elevation of BP normally seen in adult rats exposed to glucocorticoids in utero. ${ }^{54}$ In addition, epinephrine and phenylethanolamine N-methyltransferase enzyme expression were reduced in these adult IUGR rats, implicating the involvement of DNMTs and HDAC in the epigenetic programming of hypertension in FGR. Cortisol is a glucocorticoid implicated in stress response and regulation of vascular tone. The enzyme 11-HSD2 converts cortisol to its inactive form, cortisone, and its reduction is associated with increased vascular tone via amplified pressor response of angiotensin and catecholamines. ${ }^{55}$ FGR has been shown to reduce 11-HSD2 protein and increase methylation of the gene that codes for this enzyme, which results in transcriptional repression, ${ }^{56,57}$ thus providing further evidence of epigenetic involvement in fetal programming of hypertension.

Maternal calorie restriction in rats has resulted in pulmonary hypertension in offspring characterized by aberrant proliferation, migration, and angiogenesis in the pulmonary vascular endothelial cells (PVEC). PVEC derived endothelin 1 is thought to play a role in driving endothelial dysfunction in these animals. Epigenetic analysis of sperm and PVEC samples from first-generation IUGR animals revealed that there was reduced DNA methylation and enhanced trimethylation of lysine 4 of the histone 3 protein within the first intron of the endothelin 1 (ET1) gene. In addition, PVEC samples derived from second-generation IUGR animals continued to have significant demethylation of ET1 first intron. These observations indicate a transgenerational inheritance of endothelial dysfunction through epigenetics. ${ }^{25}$

Both maternal malnutrition and dexamethasone exposure have been shown to increase Angiotensin Receptor Type 1a (AGTR1a) expression in the hypothalamic paraventricular 
nucleus, reduce DNA methyltransferase 3 (DNMT3) expression and its binding to the AGTR1a gene as well as increase DNA demethylation in that gene. ${ }^{58}$ These epigenetic modifications may be associated with the increased salt sensitive hypertensive phenotype seen in adult FGR animals. Others have demonstrated that non-coding RNAs are another epigenetic mechanism involved in hypertension pathogenicity; ${ }^{59}$ however, more research is needed to determine the extent that this type of epigenetic regulation is implicated in fetal programming of hypertension. Finally, it is paramount to note that while numerous studies have found an association between FGR/SGA/LBW and epigenetic modifications, there are few studies that have definitely linked epigenetic modifications to a phenotype, suggesting that this area requires further introspection.

\section{Role of FGR Induced Vascular Dysfunction in Fetal Programming of Hypertension}

Systemic vascular resistance is one factor that regulates BP homeostasis and is largely dependent on the patency of peripheral blood vessels. Increases in peripheral vascular resistance correlates with elevation of BP. ${ }^{1}$ Several studies have reported that FGR is associated with increased vascular resistance in humans. ${ }^{60-62}$ In both human and animal models, FGR has been shown to alter normal physical structure of blood vessels including increasing the intima media thickness ${ }^{63,64}$ and smooth muscle cell number, reducing arterial elasticity and endothelial cell volume ${ }^{65-69}$ as well as increasing collagen deposition. ${ }^{70}$ The collective evidence suggests that vascular remodeling is one mechanism whereby FGR may program adult hypertension.

Angiogenesis defects are commonly seen in FGR and may also contribute to adult hypertension. Rat and sheep models of FGR demonstrate reduced micro vessel numbers in a variety of vascular beds. ${ }^{71-73}$ In addition, during perinatal development angiogenic capacity is reduced in FGR due to deregulated expression of vascular growth and proliferation factors such as vascular endothelial growth factor (VEGF), ${ }^{1,74}$ placental growth factor and insulin growth factor. $^{75-77}$

Vascular response to physiological vasoactive compounds is an important determinant of BP regulation and subsequent risk of hypertension. ${ }^{78}$ In some FGR animal models, suboptimal fetal environments have been shown to variably affect the response of different vascular beds to physiological vasodilator and vasoconstrictor agents. ${ }^{1}$
Various in utero insults, such as maternal obesity, ${ }^{79}$ endothelial nitric oxide synthase (eNOS) deficiency, ${ }^{80}$ dexamethasone exposure ${ }^{81}$ in mice, and maternal cocaine exposure $^{82}$ in rats have been shown to increase the response of mesenteric arteries to adrenergic agonists. However, some studies did not demonstrate this response, ${ }^{83,84}$ suggesting that the effect of FGR on these arteries might be dependent on the type and timing of developmental insult. Increased sympathetic activity subsequent to FGR, particularly to the kidney, sometimes results in adrenergic receptor desensitization due to high circulating levels of catecholamines. ${ }^{1}$ Angiotensin is an important target in hypertension treatment. Several developmental insults, such as reduced uterine perfusion, $^{85}$ maternal high sucrose diet, ${ }^{86}$ fetal dexamethasone, ${ }^{87}$ and nicotine exposure ${ }^{88,89}$ alter this pathway in the vasculature (depending on the vascular bed). This leads to an elevated pressor response which may cause BP elevation. FGR has also altered endothelin resulting in an increased angiotensin pressor response. ${ }^{25}$ Other vasoconstrictor mechanisms shown to be altered and potentiated by FGR include thromboxane ${ }^{90}$ and serotonin signaling. ${ }^{91}$ In addition, increases in myogenic tone in FGR animals has been reported. ${ }^{92,93}$

Defective endothelial function can be a precursor to development of hypertension. ${ }^{94}$ FGR models of maternal nutrient restriction and high fat diet display signs of endothelial dysfunction by reduced vasodilator effects of acetylcholine in the mesenteric arteries and other vascular beds. ${ }^{83,95}$ Females are normally protected from this phenomenon unless ovariectomized. ${ }^{96}$ Vasodilatory pathways, such as eNOS, prostaglandin, ${ }^{97}$ and endothelial dependent hyperpolarization $^{98}$ may be mechanisms altered by FGR and responsible for reducing the integrity of vascular endothelial function in FGR offspring.

\section{Contribution of FGR Induced Neuroendocrine Impairment in Fetal Programming of Hypertension}

Both the nervous and endocrine systems are important regulators of BP and any functional imbalance in these two systems can result in elevated BP. ${ }^{99}$ Abundant evidence suggests that several neuroendocrine pathways are altered in FGR and may explain why disturbances in fetal life are closely associated with adult hypertension. 3,61,100-102

Several endocrine pathways are altered in FGR. Endogenous or exogenous maternal exposure to 
glucocorticoids may result in FGR, hyperactivation, and permanent alteration of the hypothalamic pituitary adrenal (HPA) axis and deregulation of BP homeostasis in offspring. ${ }^{59,102}$ Since the HPA axis is heavily involved in regulating the stress system, alterations of this pathway in FGR may lead to hypertension through stress associated mechanisms and alteration of brain mineralocorticoid and glucocorticoid receptors. ${ }^{102}$ In rats, maternal exposure to glucocorticoids increased the expression level of PNMT, an enzyme responsible for synthesis of epinephrine. Elevated epinephrine levels can increase sympathetic nervous activity resulting in hypertension. ${ }^{103}$ Leptin signaling is another hormonal pathway altered by $\mathrm{FGR}^{6,104-106}$ and impairment of this pathway may lead to a hyperphagic phenotype that becomes obese and consequently hypertensive. Alternatively, disruption in leptin signaling can lead to hypertension through sympathetic nervous activation and catecholamine secretion. ${ }^{105,107}$ Both maternal nutrient restriction and placental insufficiency can suppress the renin angiotensin system (RAS), with kidney expression of angiotensin receptor 1 (Ang R1) and circulating angiotensin II (Ang II) reduced at birth. ${ }^{108-110}$ The RAS is important in regulating nephrogenesis and kidney development. FGR rodents often have inappropriately activated Ang II-Ang R1 signaling when they become hypertensive in adulthood. ${ }^{29,109}$ In addition, angiotensin (Ang)-(1-7), the pathway that opposes the Ang II-Ang RI signaling, was downregulated in adult glucocorticoid exposed sheep. ${ }^{111,112}$ Collectively, these results suggest that the RAS system might be implicated in altering kidney structural development and physiology during fetal life and might result in hypertension in adult life. Testosterone is another hormone that is implicated in programming fetal origins of hypertension. Gonadectomy improved BP homeostasis in FGR but not in control rats in a study by Ojeda et al, ${ }^{113}$ illustrating the importance of testosterone in the developmental origins of hypertension in these animals. FGR altered the energy homeostasis hormones, insulin and visfatin ${ }^{104,105}$, which has the potential to indirectly contribute to the hypertensive phenotype through metabolic dysfunction.

FGR is often associated with sympathetic nervous system activation, presenting a potential mechanism leading to hypertension. ${ }^{3,114}$ Bilateral denervation of renal nerves protects against the hypertensive phenotype in adult male rats exposed to placental insufficiency. ${ }^{115}$ However, some investigations failed to show the association of FGR with increased sympathetic nervous activity, ${ }^{116,117}$ implying that the role of sympathetic activity in the etiology of developmentally programmed hypertension might be dependent on sex, animal model, and type and timing of the developmental insult.

\section{Impairment of Renal Anatomy and Physiology as Etiology of Fetal Programming of Hypertension}

The renal system is essential in regulating BP and alterations in its physiology often results in secondary forms of hypertension. Renal artery perfusion pressure directly controls extracellular volume and sodium excretion in a process called natriuresis; dictating the activation of several vasoactive systems including the renin angiotensin aldosterone system (RAAS), which is central in regulating BP. ${ }^{118}$ In addition, maladaptive changes in renal sodium and chloride handling have been associated with hypertensive conditions. One body of evidence suggests that renal nephron number and glomerular filtration rate are negatively associated with the risk of hypertension. ${ }^{119,120}$ Furthermore, hypertension is often characterized with increased sympathetic activity to the glomerular afferent artery. ${ }^{121,122}$ Ultimately, this data shows the importance of the kidney in maintaining BP homeostasis under normal and hypertensive pathophysiological conditions.

Alterations in kidney anatomy and physiology have been identified in IUGR and present potential links between FGR and risk for hypertension. Maternal protein restriction, hypoxia, placental insufficiency, and glucocorticoid exposure decrease nephron endowment and impair kidney anatomy in rodent offspring. ${ }^{123-126}$ In humans, deficiencies in maternal folate, vitamin A, and total energy has been associated with kidney function impairment indicated by elevated proteinuria, reduced GFR, and abnormal creatine clearance in F1 offspring. ${ }^{127}$ Crump et al showed that the risk of kidney disease was higher in preterm FGR individuals as young age as 9 years old. ${ }^{128}$ Other studies have also observed alterations in kidney function and structure in human FGR individuals, ${ }^{129,130}$ indicating that kidney development is very sensitive to developmental insults during fetal growth. Reduced nephron number may lead to hyperfiltration in the available glomerular nephrons. This may cause increased glomerular intracapillary pressure and hypertrophy which leads to diminished kidney function and subsequent hypertension. ${ }^{131}$ Alterations in kidney physiology was also shown in animals exposed to FGR, particularly in RAAS system 
suppression at birth and inappropriate activation in adult life. ${ }^{108,109}$ Furthermore, offspring of protein deprived dams show increased expression of the following sodium transport proteins before development of hypertension: the renal thick ascending limb $\mathrm{Na}^{+}-\mathrm{K}^{+}-2 \mathrm{Cl}^{-}$cotransporter, $\mathrm{Na}^{+} \mathrm{CL}^{-}$transporter ${ }^{132}$ and both the $\alpha$ and $\beta$ subunits of the apical $\mathrm{Na}^{+}-\mathrm{K}^{+}$ATPase transporter. ${ }^{23}$ However, the basal sodium excretory function in these animals was normal suggesting that renal sodium handling in these offspring might be compromised even before the progression to hypertension. Other studies have demonstrated that increased renal sympathetic activity might be responsible for the hypertensive phenotype seen in adult FGR animals since renal denervation reduces BP in FGR but not control animals. ${ }^{115,133,134}$ Overall, these observations indicate that developmental insults on the kidney during fetal growth may have profound effects on the development of hypertension in adult life.

\section{FGR Induced Obesity as Risk for Hypertension}

FGR individuals are more likely to experience adult metabolic syndrome than normal birth weight individuals. ${ }^{135}$ Metabolic Syndrome (Met S) is a group of conditions of metabolic origin which occur together and increase a patient's risk of developing cardiovascular disease. The components of Met S include but are not limited to insulin resistance, hypertension, central obesity, hyperglycemia, and dyslipidemia. ${ }^{136}$ Increased risk of developing Met $\mathrm{S}$ in FGR individuals may be due to the "catch up growth" phenomenon often observed after FGR, which is characterized by childhood compensatory accelerated growth rate. ${ }^{137}$ Rodent model investigations have shown that FGR programs a hyperphagic phenotype in infancy by increasing the expression of orexigenic pathways and suppressing anorexigenic brain signaling. This hyperphagic phenotype is thought to cause post-natal catch-up growth (PNCG) and exacerbate development of the metabolic syndrome later in life. ${ }^{6,138}$

Insulin and leptin are the two principal hormones regulating energy homeostasis; evidence indicates that FGR individuals tend to experience greater insulin and leptin resistance than their normal birth weight counterparts. ${ }^{135,139-141}$ Children and young adult FGR individuals demonstrated decreased response to insulin. ${ }^{142,143}$ Furthermore, FGR rodents demonstrated signs of insulin and leptin resistance, impaired glucose tolerance, and reduced food expenditure in early life. ${ }^{101,144}$ Leptin resistance may also contribute to obesity and hypertension by affecting renal sympathetic flow and endothelial dysfunction as well as by altering the renin-angiotensin-aldosterone system (RAAS). ${ }^{145-147}$ Although FGR newborns exhibit relatively decreased serum leptin due to lower adipose tissue, high leptin concentrations are observed in FGR individuals during catch up growth. ${ }^{140,141}$ Adult rodent FGR models exhibit increased serum leptin and indicate resistance. ${ }^{6}$ Thus, the dysfunction of this metabolic pathway may partly explain why adult FGR individuals often develop obesity and hypertension.

\section{Sex Differences in Fetal Programming of Hypertension}

In general, the prevalence of hypertension is higher in males than females, ${ }^{148-150}$ suggesting sex differences in the development and progression of hypertension. Likewise, fetal programming of hypertension is associated with sex differences. Both male and female FGR offspring exhibit hypertension before puberty; however, females become normotensive during adolescence when estrogen production peaks, ${ }^{113,151-155}$ whereas their male counterparts remain hypertensive. Ovariectomy significantly elevated $\mathrm{BP}$ in FGR but not in control rats, whereas estrogen administration returned $\mathrm{BP}$ to normal range in FGR animals. ${ }^{151}$ These results indicate that sex hormones produced by ovaries, particularly estrogen, protect FGR rats from fetal programmed hypertension.

In males, castration protects FGR offspring from elevation of BP, whereas exogenous administration of testosterone rejuvenates the hypertensive phenotype. ${ }^{113,156}$ In addition, testosterone has been shown to promote a hypertensive phenotype; animal studies have shown that its dosage is proportional to $\mathrm{BP}$ increases in animals. ${ }^{157,158}$ Sex hormones also influence the RAAS. Testosterone seems to promote RAAS activation since BP of male FGR rat offspring respond greater to angiotensin II administration than male control offspring. ${ }^{159}$

\section{Conclusion}

Although our current knowledge of the mechanisms responsible for fetal origins of hypertension is still limited, a significant body of evidence from both human and animal models suggests that suboptimal fetal environments are associated with adult development of hypertension (Figure 1). More research is required to establish the causal relationship between FGR and adult hypertension. Currently, we 


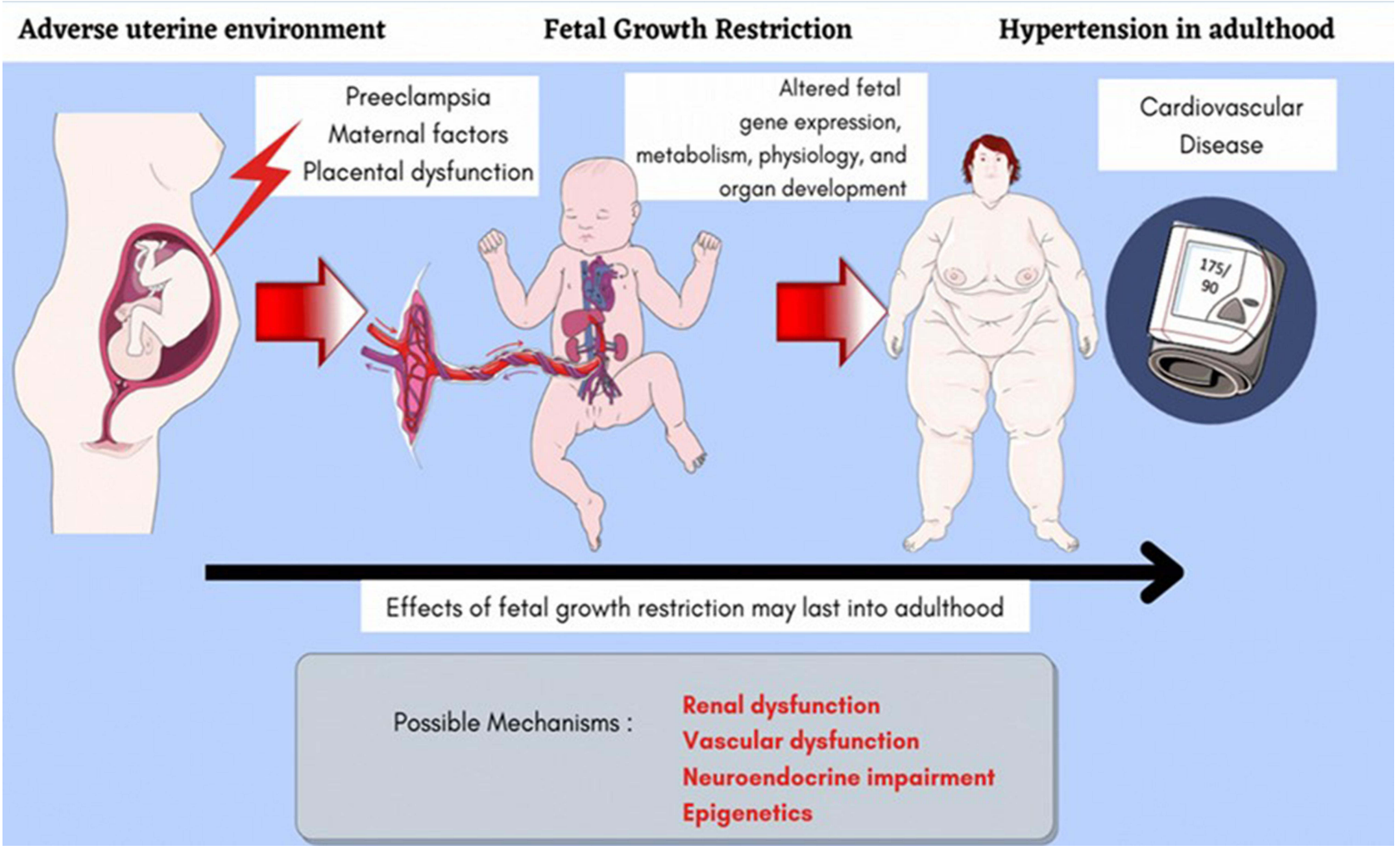

Figure I Mechanisms of fetal programming of hypertension, smart.servier.com. ${ }^{160}$

understand that FGR results in alterations in the development, anatomy, and function of several systems essential to maintaining normal physiological regulation of BP. These include the vascular, renal, neural, and endocrine systems. In addition, while huge advances in understanding fetal programming of hypertension have been made in recent decades, the therapeutic relevance of the biological pathways altered by FGR remains to be evaluated in human populations. Much research is needed if FGR pathway alterations (such as endothelin, leptin, angiotensin, and eNOS signaling pathways) can be utilized to develop drugs or prophylactic agents against hypertension in the FGR population. Lastly, more research is required to understand the time course of developmental origins of hypertension in both animals and humans. Identifying the developmental periods in which the majority of adverse adaptations occur to fetal development will allow researchers to develop time-informed interventions that may reverse or prevent these adaptations and improve the long-term health of FGR individuals.

\section{Acknowledgments}

This work is supported by S. Intapad from funds by The American Society of Nephrology Foundation for Kidney Research Norman Siegel Research Scholar grant, American
Heart Association grant 16SDG27770041, National Institute of General Medical Sciences grant P20GM109036, and Tulane University start-up funding. B. Bhunu acknowledges the support from Fulbright Association Junior Staff Development Program fellowship awarded by the United States Embassy in Zimbabwe. I. Riccio is supported by the Tulane University Newcomb Institute grant. We thank Nancy Busija, MA, CCC-SLP, for editing the manuscript.

\section{Disclosure}

The authors report no conflicts of interest in this work.

\section{References}

1. Morton JS, Cooke C-L, Davidge ST. In utero origins of hypertension: mechanisms and targets for therapy. Physiol Rev. 2016;96:549-603. doi:10.1152/physrev.00015.2015

2. Wlodek ME, Westcott K, Siebel AL, Owens JA, Moritz KM. Growth restriction before or after birth reduces nephron number and increases blood pressure in male rats. Kidney Int. 2008;74:187-195. doi:10. 1038/ki.2008.153

3. Alexander BT. Fetal programming of hypertension. Am J Physiol Regulat Integrat Comparat Physiol. 2006;290:R1-R10. doi:10.1152/ ajpregu.00417.2005

4. Yu X, Yuan Z, Lu H, et al. Relationship between birth weight and chronic kidney disease: evidence from systematics review and two-sample Mendelian randomization analysis. Hum Mol Genet. 2020;29:2261-2274. doi:10.1093/hmg/ddaa074 
5. Kanda T, Murai-Takeda A, Kawabe H, Itoh H. Low birth weight trends: possible impacts on the prevalences of hypertension and chronic kidney disease. Hypertens Res. 2020;43:859-868. doi:10.1038/s41440-020-0451-z

6. Desai M, Gayle D, Han G, Ross MG. Programmed hyperphagia due to reduced anorexigenic mechanisms in intrauterine growth-restricted offspring. Reprod Sci. 2007;14:329-337. doi: $10.1177 / 1933719107303983$

7. Drake AJ, Liu L. Intergenerational transmission of programmed effects: public health consequences. Trends Endocrinol Metabol. 2010;21:206-213. doi:10.1016/j.tem.2009.11.006

8. Barker DJ. Fetal origins of coronary heart disease. BMJ. 1995;311:171-174. doi:10.1136/bmj.311.6998.171

9. Barker DJP. Birth weight and hypertension. Hypertension. 2006;48:357-358. doi:10.1161/01.HYP.0000236552.04251.42

10. Calkins K, Devaskar SU. Fetal origins of adult disease. Curr Probl Pediatr Adolesc Health Care. 2011;41:158-176. doi:10.1016/j.cppeds.2011.01.001

11. Alexander BT. Placental insufficiency leads to development of hypertension in growth-restricted offspring. Hypertension. 2003;41:457-462. doi:10.1161/01.HYP.0000053448.95913.3D

12. Brodsky D, Christou H. Current concepts in intrauterine growth restriction. J Intensive Care Med. 2004;19:307-319. doi:10.1177/ 0885066604269663

13. Chatmethakul T, Roghair RD. Risk of hypertension following perinatal adversity: IUGR and prematurity. $J$ Endocrinol. 2019;242:T21-T32. doi:10.1530/JOE-18-0687

14. Armengaud JB, Yzydorczyk C, Siddeek B, Peyter AC, Simeoni U. Intrauterine growth restriction: clinical consequences on health and disease at adulthood. Reprod Toxicol. 2021;99:168-176. doi:10.1016/j.reprotox.2020.10.005

15. Cutland CL, Lackritz EM, Mallett-Moore T, et al.; Brighton Collaboration Low Birth Weight Working G. Low birth weight: case definition \& guidelines for data collection, analysis, and presentation of maternal immunization safety data. Vaccine. 2017;35:6492-6500. doi:10.1016/j.vaccine.2017.01.049

16. Raju TNK, Pemberton VL, Saigal S, Blaisdell CJ, Moxey-Mims $\mathrm{M}$, Buist S. Long-term healthcare outcomes of preterm birth: an executive summary of a conference sponsored by the National Institutes of Health. J Pediatr. 2017;181:309-318.e1. doi:10. 1016/j.jpeds.2016.10.015

17. Martin JA, Hamilton BE, Osterman MJK, Driscoll AK. Births: final data for 2019. Natl Vital Stat Rep. 2021;70:1-51.

18. Jin J. Babies with low birth weight. JAMA. 2015;313:432. doi:10.1001/jama.2014.3698

19. Barry JS, Rozance PJ, Anthony RV. An animal model of placental insufficiency-induced intrauterine growth restriction. Semin Perinatol. 2008;32:225-230. doi:10.1053/j.semperi.2007.11.004

20. Ventolini G, Neiger R. Placental dysfunction: pathophysiology and clinical considerations. $J$ Obstet Gynaecol. 2006;26: 728-730. doi:10.1080/01443610600955685

21. Burton GJ, Jauniaux E. Pathophysiology of placental-derived fetal growth restriction. Am J Obstet Gynecol. 2018;218:S745s761. doi:10.1016/j.ajog.2017.11.577

22. Burton GJ, Redman CW, Roberts JM, Moffett A. Pre-eclampsia: pathophysiology and clinical implications. BMJ. 2019;366:12381. doi:10.1136/bmj.12381

23. Bertram C, Trowern AR, Copin N, Jackson AA, Whorwood CB. The maternal diet during pregnancy programs altered expression of the glucocorticoid receptor and type 2 11ß-hydroxysteroid dehydrogenase: potential molecular mechanisms underlying the programming of hypertension in utero. Endocrinology. 2001;142:2841-2853. doi:10.1210/endo.142.7.8238

24. Wardinger JE, Ambati S. Placental Insufficiency. Treasure Island (FL): StatPearls Publishing Copyright (C) 2021, StatPearls Publishing LLC.; 2021.
25. Zhang $\mathrm{Z}$, Luo $\mathrm{X}, \mathrm{Lv} \mathrm{Y}$, et al. Intrauterine growth restriction programs intergenerational transmission of pulmonary arterial hypertension and endothelial dysfunction via sperm epigenetic modifications. Hypertension. 2019;74:1160-1171. doi:10.1161/ HYPERTENSIONAHA.119.13634

26. Lackland DT, Egan BM, Ferguson PL. Low birth weight as a risk factor for hypertension. J Clin Hypertens. 2003;5:133-136. doi:10.1111/j.1524-6175.2003.01353.x

27. Zarrati M, Shidfar F, Razmpoosh E, et al. Does low birth weight predict hypertension and obesity in schoolchildren? Ann Nutr Metab. 2013;63:69-76. doi:10.1159/000351869

28. Curhan GC, Chertow GM, Willett WC, et al. Birth weight and adult hypertension and obesity in women. Circulation. 1996;94:1310-1315. doi:10.1161/01.CIR.94.6.1310

29. Dasinger JH, Intapad S, Backstrom MA, Carter AJ, Alexander BT. Intrauterine growth restriction programs an accelerated age-related increase in cardiovascular risk in male offspring. Am J Physiol Renal Physiol. 2016;311:F312-F319. doi:10.1152/ajprenal.00123.2016

30. Curhan GC, Willett WC, Rimm EB, Spiegelman D, Ascherio AL, Stampfer MJ. Birth weight and adult hypertension, diabetes mellitus, and obesity in US men. Circulation. 1996;94:3246-3250. doi:10.1161/01.CIR.94.12.3246

31. Lai C, Hu Y, He D, et al. U-shaped relationship between birth weight and childhood blood pressure in China. BMC Pediatr. 2019;19:264. doi:10.1186/s12887-019-1638-9

32. Bhat R, Salas AA, Foster C, Carlo WA, Ambalavanan N. Prospective analysis of pulmonary hypertension in extremely low birth weight infants. Pediatrics. 2012;129:e682-e689. doi:10.1542/peds.2011-1827

33. Shankaran S, Das A, Bauer CR, et al. Fetal origin of childhood disease: intrauterine growth restriction in term infants and risk for hypertension at 6 years of age. Arch Pediatr Adolesc Med. 2006;160:977-981. doi:10.1001/archpedi.160.9.977

34. Centra JC, Roberts G, Opie G, Cheong J, Doyle LW. Masked hypertension in extremely preterm adolescents. $J$ Paediatr Child Health. 2015;51:1060-1065. doi:10.1111/jpc. 12928

35. Law CM, de Swiet M, Osmond C, et al. Initiation of hypertension in utero and its amplification throughout life. $\mathrm{Br}$ Med $\mathrm{J}$. 1993;306:24-27. doi:10.1136/bmj.306.6869.24

36. Johansson S, Iliadou A, Bergvall N, Tuvemo T, Norman M, Cnattingius S. Risk of high blood pressure among young men increases with the degree of immaturity at birth. Circulation. 2005;112:3430-3436. doi:10.1161/CIRCULATIONAHA.105.54 0906

37. Gatford KL, Andraweera PH, Roberts CT, Care AS. Animal models of preeclampsia. Hypertension. 2020;75:1363-1381. doi:10.1161/HYPERTENSIONAHA.119.14598

38. Intapad S, Dasinger JH, Johnson JM, Brown AD, Ojeda NB, Alexander BT. Male and female intrauterine growth-restricted offspring differ in blood pressure, renal function, and glucose homeostasis responses to a postnatal diet high in fat and sugar. Hypertension. 2019;73:620-629. doi:10.1161/ HYPERTENSIONAHA.118.12134

39. Girardi G, Yarilin D, Thurman JM, Holers VM, Salmon JE. Complement activation induces dysregulation of angiogenic factors and causes fetal rejection and growth restriction. J Exp Med. 2006;203:2165-2175. doi:10.1084/ jem.20061022

40. Sathishkumar K, Elkins R, Yallampalli U, Yallampalli C. Protein restriction during pregnancy induces hypertension in adult female rat offspring-influence of oestradiol. $B r \quad J$ Nutr. 2012;107: 665-673. doi:10.1017/S0007114511003448

41. Vehaskari VM, Aviles DH, Manning J. Prenatal programming of adult hypertension in the rat. Kidney Int. 2001;59:238-245. doi:10.1046/j.1523-1755.2001.00484.x 
42. Hsu CN, Lin YJ, Yu HR, et al. Protection of male rat offspring against hypertension programmed by prenatal dexamethasone administration and postnatal high-fat diet with the Nrf2 activator dimethyl fumarate during pregnancy. Int J Mol Sci. 2019;20:3957. doi:10.3390/ijms20163957

43. Sutton EF, Lob HE, Song J, et al. Adverse metabolic phenotype of female offspring exposed to preeclampsia in utero: a characterization of the $\mathrm{BPH} / 5$ mouse in postnatal life. $A m$ J Physiol Regul Integr Comp Physiol. 2017;312:R485-R491. doi:10.1152/ajpregu.00512.2016

44. Sharkey LC, McCune SA, Yuan O, Lange C, Fray J. Spontaneous pregnancy-induced hypertension and intrauterine growth restriction in rats. Am J Hypertens. 2001;14:1058-1066. doi:10.1016/ S0895-7061(01)02161-6

45. Guberman C, Jellyman JK, Han G, Ross MG, Desai M. Maternal high-fat diet programs rat offspring hypertension and activates the adipose renin-angiotensin system. Am J Obstet Gynecol. 2013;209:262.e1-8. doi:10.1016/j.ajog.2013.05.023

46. O’Sullivan L, Little MH, Combes AN, Moritz KM. Epigenetics and developmental programming of adult onset diseases. Pediatr Nephrol. 2012;27:2175-2182. doi:10.1007/s00467-012-2108-x

47. Natarajan R. Epigenetic mechanisms in diabetic vascular complications and metabolic memory: the 2020 Edwin Bierman award lecture. Diabetes. 2021;70:328-337. doi:10.2337/dbi200030

48. Wang J, Gong L, Tan Y, Hui R, Wang Y. Hypertensive epigenetics: from DNA methylation to microRNAs. J Hum Hypertens. 2015;29:575-582. doi:10.1038/jhh.2014.132

49. Chelladurai P, Boucherat O, Stenmark K, et al. Targeting histone acetylation in pulmonary hypertension and right ventricular hypertrophy. Br J Pharmacol. 2021;178:54-71. doi:10.1111/ bph.14932

50. Ling C, Rönn T. Epigenetics in human obesity and type 2 diabetes. Cell Metab. 2019;29:1028-1044. doi:10.1016/j.cmet.20 19.03.009

51. Chhabra R. Chapter 4 - the epigenetics of noncoding RNA. In: Tollefsbol TO, editor. Handbook of Epigenetics. Second ed. Academic Press; 2017:47-59.

52. Liang M. Epigenetic mechanisms and hypertension. Hypertension. 2018;72:1244-1254. doi:10.1161/HYPERTENSIONAHA.118.11 171

53. Pinney SE, Simmons RA. Epigenetic mechanisms in the development of type 2 diabetes. Trends Endocrinol Metabol. 2010;21:223-229. doi:10.1016/j.tem.2009.10.002

54. Lamothe J, Khurana S, Tharmalingam S, et al. The role of DNMT and HDACs in the fetal programming of hypertension by glucocorticoids. Oxid Med Cell Longev. 2020;2020:5751768. doi: $10.1155 / 2020 / 5751768$

55. Souness GW, Brem AS, Morris DJ. 11 1 -hydroxysteroid dehydrogenase antisense affects vascular contractile response and glucocorticoid metabolism. Steroids. 2002;67:195-201. doi:10.1016/ S0039-128X(01)00148-9

56. Jensen Peña C, Monk C, Champagne FA. Epigenetic effects of prenatal stress on $11 \beta$-hydroxysteroid dehydrogenase- 2 in the placenta and fetal brain. PLoS One. 2012;7:e39791. doi:10.1371/journal.pone.0039791

57. Whorwood CB, Firth KM, Budge H, Symonds M. Maternal undernutrition during early to midgestation programs tissuespecific alterations in the expression of the glucocorticoid receptor, 11 $\beta$-hydroxysteroid dehydrogenase isoforms, and type 1 angiotensin II receptor in neonatal sheep 1. Endocrinology. 2001;142:2854-2864. doi:10.1210/endo.142.7.8264

58. Kawakami-Mori F, Nishimoto M, Reheman L, et al. Aberrant DNA methylation of hypothalamic angiotensin receptor in prenatal programmed hypertension. JCI Insight. 2018;3. doi:10.1172/ jci.insight. 95625
59. Anwar MA, Saleh AI, Al Olabi R, Al Shehabi TS, Eid AH Glucocorticoid-induced fetal origins of adult hypertension: association with epigenetic events. Vascul Pharmacol. 2016;82:41-50. doi:10.1016/j.vph.2016.02.002

60. Goh KL, Shore AC, Quinn M, Tooke JE. Impaired microvascular vasodilatory function in 3-month-old infants of low birth weight. Diabetes Care. 2001;24:1102-1107. doi:10.2337/diacare.24.6.1102

61. Martin H, Gazelius B, Norman M. Impaired acetylcholine-induced vascular relaxation in low birth weight infants: implications for adult hypertension? Pediatr Res. 2000;47:457-462. doi:10.1203/00006450-200004000-00008

62. Yzydorczyk C, Armengaud J-B, Peyter A-C, et al. Endothelial dysfunction in individuals born after fetal growth restriction: cardiovascular and renal consequences and preventive approaches. J Dev Orig Health Dis. 2017;8:1-17. doi:10.1017/ S2040174417000265

63. Crispi F, Figueras F, Cruz-Lemini M, Bartrons J, Bijnens B, Gratacos E. Cardiovascular programming in children born small for gestational age and relationship with prenatal signs of severity. Am J Obstet Gynecol. 2012;207:121.e1-9. doi:10.1016/j.ajog. 2012.05.011

64. Crispi F, Bijnens B, Figueras F, et al. Fetal growth restriction results in remodeled and less efficient hearts in children. Circulation. 2010;121:2427-2436. doi:10.1161/CIRCULATIONAHA.110.93 7995

65. Armitage JA, Lakasing L, Taylor PD, et al. Developmental programming of aortic and renal structure in offspring of rats fed fat-rich diets in pregnancy. $J$ Physiol. 2005;565:171-184. doi:10.1113/jphysiol.2005.084947

66. Khorram O, Momeni M, Ferrini M, Desai M, Ross MG. In utero undernutrition in rats induces increased vascular smooth muscle content in the offspring. Am J Obstet Gynecol. 2007;196:486.e1486.e8. doi:10.1016/j.ajog.2007.01.020

67. Piecha G, Koleganova N, Ritz E, et al. High salt intake causes adverse fetal programming-vascular effects beyond blood pressure. Nephrol Dial Transplant. 2012;27:3464-3476. doi:10.1093/ ndt/gfs027

68. Pascoe K, Wlodek M, Jones G. Increased elastic tissue defect formation in the growth restricted brown Norway rat: a potential link between in utero condition and cardiovascular disease. Pediatr Res. 2008;64:125-130. doi:10.1203/PDR.0b013e3181 761859

69. Salinas C, Blanco C, Villena $M$, et al. Cardiac and vascular disease prior to hatching in chick embryos incubated at high altitude. J Dev Orig Health Dis. 2010;1:60-66. doi:10.1017/ S2040174409990043

70. Dodson RB, Rozance PJ, Petrash CC, Hunter KS, Ferguson VL. Thoracic and abdominal aortas stiffen through unique extracellular matrix changes in intrauterine growth restricted fetal sheep. Am J Physiol Heart Circ Physiol. 2014;306:H429-H437. doi:10.1152/ajpheart.00472.2013

71. Dunford LJ, Sinclair KD, Kwong WY, et al. Maternal protein-energy malnutrition during early pregnancy in sheep impacts the fetal ornithine cycle to reduce fetal kidney microvascular development. FASEB J. 2014;28:4880-4892. doi:10.1096/ fj.14-255364

72. Pladys P, Sennlaub F, Brault S, et al. Microvascular rarefaction and decreased angiogenesis in rats with fetal programming of hypertension associated with exposure to a low-protein diet in utero. Am J Physiol Regulat Integrat Comparat Physiol. 2005;289:R1580-R1588. doi:10.1152/ajpregu.00031.2005

73. Rozance PJ, Seedorf GJ, Brown A, et al. Intrauterine growth restriction decreases pulmonary alveolar and vessel growth and causes pulmonary artery endothelial cell dysfunction in vitro in fetal sheep. Am J Physiol Lung Cell Mol Physiol. 2011;301: L860-L871. doi:10.1152/ajplung.00197.2011 
74. Voller SB, Chock S, Ernst LM, et al. Cord blood biomarkers of vascular endothelial growth (VEGF and sFlt-1) and postnatal growth: a preterm birth cohort study. Early Hum Dev. 2014;90:195-200. doi:10.1016/j.earlhumdev.2014.01.003

75. Burkhardt T, Matter CM, Lohmann C, et al. Decreased umbilical artery compliance and igf-I plasma levels in infants with intrauterine growth restriction - implications for fetal programming of hypertension. Placenta. 2009;30:136-141. doi:10.1016/j.placenta. 2008.11.005

76. Zhu MJ, Du M, Nijland MJ, et al. Down-regulation of growth signaling pathways linked to a reduced cotyledonary vascularity in placentomes of over-nourished, obese pregnant ewes. Placenta. 2009;30:405-410. doi:10.1016/j.placenta.2009.02.001

77. Sesso R, Franco MCP. Abnormalities in metalloproteinase pathways and IGF-I axis: a link between birth weight, hypertension, and vascular damage in childhood. Am $J$ Hypertens. 2010;23:6-11. doi:10.1038/ajh.2009.200

78. Touyz RM, Alves-Lopes R, Rios FJ, et al. Vascular smooth muscle contraction in hypertension. Cardiovasc Res. 2018;114:529-539. doi:10.1093/cvr/cvy023

79. Samuelsson A-M, Matthews PA, Argenton M, et al. Diet-induced obesity in female mice leads to offspring hyperphagia, adiposity, hypertension, and insulin resistance. Hypertension. 2008;51:38 3-392. doi:10.1161/HYPERTENSIONAHA.107.101477

80. Roghair RD, Segar JL, Volk KA, et al. Vascular nitric oxide and superoxide anion contribute to sex-specific programmed cardiovascular physiology in mice. Am J Physiol Regul Integr Comp Physiol. 2009;296:R651-R662. doi:10.1152/ajpregu.90756.2008

81. O’Regan D, Kenyon CJ, Seckl JR, Holmes MC. Prenatal dexamethasone 'programmes' hypotension, but stress-induced hypertension in adult offspring. $J$ Endocrinol. 2008;196:343-352. doi:10.1677/JOE-07-0327

82. Xiao D, Huang X, Xu Z, Yang S, Zhang L. Prenatal cocaine exposure differentially causes vascular dysfunction in adult offspring. Hypertension. 2009;53:937-943. doi:10.1161/ HYPERTENSIONAHA.108.121830

83. Brawley L, Itoh S, Torrens $\mathrm{C}$, et al. Dietary protein restriction in pregnancy induces hypertension and vascular defects in rat male offspring. Pediatr Res. 2003;54:83-90. doi:10.1203/01. PDR.0000065731.00639.02

84. Camm EJ, Hansell JA, Kane AD, et al. Partial contributions of developmental hypoxia and undernutrition to prenatal alterations in somatic growth and cardiovascular structure and function. $\mathrm{Am}$ J Obstet Gynecol. 2010;203:495.e24-495.e34. doi:10.1016/j. ajog.2010.06.046

85. Ojeda NB, Royals TP, Alexander BT. Sex differences in the enhanced responsiveness to acute angiotensin II in growth-restricted rats: role of fasudil, a Rho kinase inhibitor. Am J Physiol Renal Physiol. 2013;304:F900-F907. doi:10.1152/ ajprenal.00687.2012

86. Li S, Fang Q, Zhou A, et al. Intake of high sucrose during pregnancy altered large-conductance $\mathrm{Ca} 2+$-activated $\mathrm{K}+$ channels and vessel tone in offspring's mesenteric arteries. Hypertens Res. 2012;36:158-165.

87. Roghair RD, Miller FJ, Scholz TD, Lamb FS, Segar JL. Coronary constriction to angiotensin II is enhanced by endothelial superoxide production in sheep programmed by dexamethasone. Pediatr Res. 2008;63:370-374. doi:10.1203/PDR.0b013e3181659bfa

88. Xiao D, Huang X, Yang S, Zhang L. Estrogen normalizes perinatal nicotine-induced hypertensive responses in adult female rat offspring. Hypertension. 2013;61:1246-1254. doi:10.1161/ HYPERTENSIONAHA.113.01152

89. Xiao D, Dasgupta C, Li Y, Huang X, Zhang L. Perinatal nicotine exposure increases angiotensin II receptor-mediated vascular contractility in adult offspring. PLoS One. 2014;9:e108161. doi:10.1371/journal.pone. 0108161
90. Chechi K, McGuire JJ, Cheema SK. An interaction of the preand post-weaning diets rich in omega- 6 polyunsaturated fats alters plasma lipids, hepatic gene expression and aortic vascular reactivity in adult C57BL/6 mice. Nutr Metab Insights. 2010;3:69-78. doi:10.4137/NMI.S6026

91. Goyal R, Papamatheakis D, Loftin M, et al. Long-term maternal hypoxia: the role of extracellular $\mathrm{Ca} 2+$ entry during serotonin-mediated contractility in fetal ovine pulmonary arteries. Reprod Sci. 2011;18:948-962. doi:10.1177/19337191 11401660

92. Hemmings DG, Williams SJ, Davidge ST. Increased myogenic tone in 7-month-old adult male but not female offspring from rat dams exposed to hypoxia during pregnancy. Am J Physiol Heart Circ Physiol. 2005;289:H674-H682. doi:10.1152/ajpheart.00191. 2005

93. Veerareddy S, Campbell ME, Williams SJ, Baker PN, Davidge ST. Myogenic reactivity is enhanced in rat radial uterine arteries in a model of maternal undernutrition. Am J Obstet Gynecol. 2004;191:334-339. doi:10.1016/j.ajog.2003.12.030

94. Krause BJ, Carrasco-Wong I, Caniuguir A, Carvajal J, Farías M, Casanello P. Endothelial eNOS/arginase imbalance contributes to vascular dysfunction in IUGR umbilical and placental vessels. Placenta. 2013;34:20-28. doi:10.1016/j.placenta.2012.09.015

95. Franco Mdo C, Dantas AP, Akamine EH, et al. Enhanced oxidative stress as a potential mechanism underlying the programming of hypertension in utero. $J$ Cardiovasc Pharmacol. 2002;40:501-509. doi:10.1097/00005344-200210000-00002

96. Musha Y, Itoh S, Hanson M, Kinoshita K. Does estrogen affect the development of abnormal vascular function in offspring of rats fed a low-protein diet in pregnancy? Pediatr Res. 2006;59:784-789. doi:10.1203/01.pdr.0000219126.78372.c8

97. Torrens C, Brawley L, Anthony FW, et al. Folate supplementation during pregnancy improves offspring cardiovascular dysfunction induced by protein restriction. Hypertension. 2006;47:982-987. doi:10.1161/01.HYP.0000215580.43711.d1

98. Shukla P, Ghatta S, Dubey N, et al. Maternal nutrient restriction during pregnancy impairs an endothelium-derived hyperpolarizing factor-like pathway in sheep fetal coronary arteries. $\mathrm{Am}$ J Physiol Heart Circ Physiol. 2014;307:H134-H142. doi:10. 1152/ajpheart.00595.2013

99. Chopra S, Baby C, Jacob JJ. Neuro-endocrine regulation of blood pressure. Indian J Endocrinol Metab. 2011;15(Suppl 4):S281S288. doi: $10.4103 / 2230-8210.86860$

100. Fu Q, McKnight RA, Callaway CW, Yu X, Lane RH, Majnik AV. Intrauterine growth restriction disrupts developmental epigenetics around distal growth hormone response elements on the rat hepatic IGF-1 gene. FASEB J. 2015;29:1176-1184. doi:10.1096/fj.14258442

101. Coupé B, Grit I, Hulin P, Randuineau G, Parnet P. Postnatal growth after intrauterine growth restriction alters central leptin signal and energy homeostasis. PLoS One. 2012;7:e30616. doi:10.1371/journal.pone.0030616

102. Kapoor A, Dunn E, Kostaki A, Andrews MH, Matthews SG. Fetal programming of hypothalamo-pituitary-adrenal function: prenatal stress and glucocorticoids. J Physiol. 2006;572:31-44. doi:10.1113/jphysiol.2006.105254

103. Khurana S, Grandbois J, Tharmalingam S, et al. Fetal programming of adrenal PNMT and hypertension by glucocorticoids in WKY rats is dose and sex-dependent. PLoS One. 2019;14: e0221719-e0221719. doi:10.1371/journal.pone.0221719

104. Nüsken K-D, Dötsch JR, Rauh M, Rascher W, Schneider H. Uteroplacental insufficiency after bilateral uterine artery ligation in the rat: impact on postnatal glucose and lipid metabolism and evidence for metabolic programming of the offspring by sham operation. Endocrinology. 2008;149:1056-1063. doi:10.1210/ en.2007-0891 
105. Satoh N, Ogawa Y, Katsuura G, et al. Sympathetic activation of leptin via the ventromedial hypothalamus: leptin-induced increase in catecholamine secretion. Diabetes. 1999;48:1787-1793. doi:10.2337/diabetes.48.9.1787

106. Kitsuda K, Yamaguchi R, Nagata E. Hypertrophic fat cells in hypophagic intrauterine growth restricted rats without catch-up growth. Kitasato Med J. 2014;44:38-46.

107. Phillips BG, Kato M, Narkiewicz K, Choe I, Somers VK. Increases in leptin levels, sympathetic drive, and weight gain in obstructive sleep apnea. Am J Physiol Heart Circulat Physiol. 2000;279:H234-H237. doi:10.1152/ajpheart.2000.279.1.H234

108. Alwasel SH, Kaleem I, Sahajpal V, Ashton N. Maternal protein restriction reduces angiotensin II AT(1) and $\mathrm{AT}(2)$ receptor expression in the fetal rat kidney. Kidney Blood Press Res. 2010;33:251-259. doi:10.1159/000317739

109. Grigore D, Ojeda NB, Robertson EB, et al. Placental insufficiency results in temporal alterations in the renin angiotensin system in male hypertensive growth restricted offspring. Am J Physiol Regul Integr Comp Physiol. 2007;293:R804-R811. doi:10.1152/ ajpregu.00725.2006

110. Woods LL, Ingelfinger JR, Nyengaard JR, Rasch R. Maternal protein restriction suppresses the newborn renin-angiotensin system and programs adult hypertension in rats. Pediatr Res. 2001;49:460-467. doi:10.1203/00006450-200104000-00005

111. Shaltout HA, Figueroa JP, Rose JC, Diz DI, Chappell MC. Alterations in circulatory and renal angiotensin-converting enzyme and angiotensin-converting enzyme 2 in fetal programmed hypertension. Hypertension. 2009;53:404-408. doi:10.1161/HYPERTENSIONAHA.108.124339

112. Su Y, Bi J, Pulgar VM, Chappell MC, Rose JC. Antenatal betamethasone attenuates the angiotensin-(1-7)-Mas receptor-nitric oxide axis in isolated proximal tubule cells. Am J Physiol Renal Physiol. 2017;312:F1056-F1062. doi:10.1152/ajprenal.00593. 2016

113. Ojeda NB, Grigore D, Yanes LL, et al. Testosterone contributes to marked elevations in mean arterial pressure in adult male intrauterine growth restricted offspring. Am J Physiol Regul Integr Comp Physiol. 2007;292:R758-R763. doi:10.1152/ajpregu.003 11.2006

114. IJzerman RG, Stehouwer CDA, Geus EJ, Weissenbruch MM, Waal HAD, Boomsma DI. Low birth weight is associated with increased sympathetic activity. Circulation. 2003;108:566-571. doi:10.1161/01.CIR.0000081778.35370.1B

115. Ojeda N, Johnson W, Dwyer T, Alexander B. Early renal denervation prevents development of hypertension in growth-restricted offspring. Clin Exp Pharmacol Physiol. 2007;34:1212-1216. doi:10.1111/j.1440-1681.2007.04754.x

116. Jansson T, Lambert GW. Effect of intrauterine growth restriction on blood pressure, glucose tolerance and sympathetic nervous system activity in the rat at 3-4 months of age. $J$ Hypertens. 1999;17:1239-1248. doi:10.1097/00004872-199917090-00002

117. Weitz G, Fehm HL, Dodt C. Low birth weight and increased sympathetic activity. Circulation. 2004;109:e30. doi:10.1161/01. CIR.0000115205.70330.05

118. Wadei HM, Textor SC. The role of the kidney in regulating arterial blood pressure. Nat Rev Nephrol. 2012;8:602-609. doi:10.1038/nrneph.2012.191

119. Tsuboi N, Sasaki T, Okabayashi Y, Haruhara K, Kanzaki G, Yokoo T. Assessment of nephron number and single-nephron glomerular filtration rate in a clinical setting. Hypertens Res. 2021;44:605-617. doi:10.1038/s41440-020-00612-y

120. Rothermund L, Nierhaus M, Fialkowski O, et al. Genetic low nephron number hypertension is associated with dysregulation of the hepatic and renal insulin-like growth factor system during nephrogenesis. J Hypertens. 2006;24:1857-1864. doi:10.1097/ 01.hjh.0000242411.50536.b9
121. Witkowski A, Prejbisz A, Florczak E, et al. Effects of renal sympathetic denervation on blood pressure, sleep apnea course, and glycemic control in patients with resistant hypertension and sleep apnea. Hypertension. 2011;58:559-565. doi:10.1161/ HYPERTENSIONAHA.111.173799

122. Fontes MAP, Marzano LAS, Silva CC, Silva ACSE. Renal sympathetic denervation for resistant hypertension: where do we stand after more than a decade. J Bras Nefrol. 2020;42:67-76. doi:10.1590/2175-8239-jbn-2018-0213

123. Gallo LA, Tran M, Cullen-McEwen LA, et al. Transgenerational programming of fetal nephron deficits and sex-specific adult hypertension in rats. Reprod Fertil Dev. 2014;26:1032-1043. doi:10.1071/RD13133

124. Singh RR, Cuffe JS, Moritz KM. Short- and long-term effects of exposure to natural and synthetic glucocorticoids during development. Clin Exp Pharmacol Physiol. 2012;39:979-989. doi:10.1111/1440-1681.12009

125. Benz K, Amann K. Maternal nutrition, low nephron number and arterial hypertension in later life. Biochimica et Biophysica Acta. 2010;1802:1309-1317. doi:10.1016/j.bbadis.2010.03.002

126. Ross B, McIntosh M, Rodaros D, Hébert TE, Rohlicek CV. Systemic arterial pressure at maturity in rats following chronic hypoxia in early life. Am J Hypertens. 2010;23:1228-1233. doi:10.1038/ajh.2010.160

127. Lee YQ, Collins CE, Gordon A, Rae KM, Pringle KG. The relationship between maternal nutrition during pregnancy and offspring kidney structure and function in humans: a systematic review. Nutrients. 2018;10:241.

128. Crump C, Sundquist J, Winkleby MA, Sundquist K. Preterm birth and risk of chronic kidney disease from childhood into mid-adulthood: national cohort study. BMJ. 2019;365:11346. doi:10.1136/bmj.11346

129. Mañalich R, Reyes L, Herrera M, Melendi C, Fundora I. Relationship between weight at birth and the number and size of renal glomeruli in humans: a histomorphometric study. Kidney Int. 2000;58:770-773. doi:10.1046/j.1523-1755.2000.00225.x

130. Hinchliffe SA, Lynch MR, Sargent PH, Howard CV, Van Velzen D. The effect of intrauterine growth retardation on the development of renal nephrons. $\mathrm{Br} J$ Obstet Gynaecol. 1992;99:296-301.

131. Hershkovitz D, Burbea Z, Skorecki K, Brenner BM. Fetal programming of adult kidney disease: cellular and molecular mechanisms. Clin J Am Soc Nephrol. 2007;2:334-342. doi:10.2215/CJN.03291006

132. Manning J, Beutler K, Knepper MA, Vehaskari VM. Upregulation of renal BSC1 and TSC in prenatally programmed hypertension. Am J Physiol Renal Physiol. 2002;283:F202-F206. doi:10.1152/ajprenal.00358.2001

133. Alexander BT, Hendon AE, Ferril G, Dwyer TM. Renal denervation abolishes hypertension in low-birth-weight offspring from pregnant rats with reduced uterine perfusion. Hypertension. 2005;45:754-758. doi:10.1161/01.HYP.0000153319.20340.2a

134. Intapad S, Tull FL, Brown AD, et al. Renal denervation abolishes the age-dependent increase in blood pressure in female intrauterine growth-restricted rats at 12 months of age. Hypertension. 2013;61:828-834. doi:10.1161/HYPERTENSIONAHA.111.00645

135. Barker DJ, Hales CN, Fall CH, Osmond C, Phipps K, Clark PM. Type 2 (non-insulin-dependent) diabetes mellitus, hypertension and hyperlipidaemia (syndrome $\mathrm{X}$ ): relation to reduced fetal growth. Diabetologia. 1993;36:62-67. doi:10.1007/BF00399095

136. Kaur J. A comprehensive review on metabolic syndrome. Cardiol Res Pract. 2014;2014:943162. doi:10.1155/2014/943162

137. Eriksson JG, Forsén T, Tuomilehto J, Jaddoe VWV, Osmond C, Barker DJP. Effects of size at birth and childhood growth on the insulin resistance syndrome in elderly individuals. Diabetologia. 2002;45:342-348. doi:10.1007/s00125-001-0757-6 
138. Shin B-C, Dai Y, Thamotharan M, Gibson LC, Devaskar SU. Preand postnatal calorie restriction perturbs early hypothalamic neuropeptide and energy balance. $J$ Neurosci Res. 2012;90:1169-1182. doi:10.1002/jnr.23013

139. Lithell HO, McKeigue PM, Berglund L, Mohsen R, Lithell UB, Leon DA. Relation of size at birth to non-insulin dependent diabetes and insulin concentrations in men aged 50-60 years. BMJ. 1996;312:406-410. doi:10.1136/bmj.312.7028.406

140. Jaquet D, Leger J, Levy-Marchal C, Oury JF, Czernichow P. Ontogeny of leptin in human fetuses and newborns: effect of intrauterine growth retardation on serum leptin concentrations. J Clin Endocrinol Metab. 1998;83:1243-1246. doi:10.1210/jcem.83.4.4731

141. Jaquet D, Leger J, Tabone MD, Czernichow P, Levy-Marchal C. High serum leptin concentrations during catch-up growth of children born with intrauterine growth retardation. J Clin Endocrinol Metab. 1999;84:1949-1953.

142. Hofman PL, Cutfield WS, Robinson EM, et al. Insulin resistance in short children with intrauterine growth retardation. J Clin Endocrinol Metab. 1997;82:402-406.

143. Jensen CB, Storgaard H, Dela F, Holst JJ, Madsbad S, Vaag AA. Early differential defects of insulin secretion and action in 19-year-old caucasian men who had low birth weight. Diabetes. 2002;51:1271-1280. doi:10.2337/diabetes.51.4.1271

144. Simmons RA, Templeton LJ, Gertz SJ. Intrauterine growth retardation leads to the development of type 2 diabetes in the rat. Diabetes. 2001;50:2279-2286. doi:10.2337/diabetes.50.10.2279

145. Mark AL, Agassandian K, Morgan DA, Liu X, Cassell MD, Rahmouni K. Leptin signaling in the nucleus tractus solitarii increases sympathetic nerve activity to the kidney. Hypertension. 2009;53:375-380. doi:10.1161/HYPERTENSIONAHA.108.124255

146. Bełtowski J, Wójcicka G, Jamroz-Wiśniewska A, Marciniak A. Resistance to acute NO-mimetic and EDHF-mimetic effects of leptin in the metabolic syndrome. Life Sci. 2009;85:557-567. doi:10.1016/j.1fs.2009.08.002

147. Santos EL, de Picoli Souza K, Da Silva ED, et al. Long term treatment with ACE inhibitor enalapril decreases body weight gain and increases life span in rats. Biochem Pharmacol. 2009;78:951-958. doi:10.1016/j.bcp.2009.06.018

148. Manning J, Vehaskari VM. Low birth weight-associated adult hypertension in the rat. Pediatr Nephrol. 2001;16:417-422. doi:10.1007/s004670000560

149. Poladia DP, Kish K, Kutay B, Bauer J, Baum M, Bates CM. Link between reduced nephron number and hypertension: studies in a mutant mouse model. Pediatr Res. 2006;59:489-493. doi:10.1203/01.pdr.0000202764.02295.45
150. Rosamond W, Flegal K, Friday G, et al. Heart disease and stroke statistics-2007 update: a report from the American Heart Association Statistics Committee and Stroke Statistics Subcommittee. Circulation. 2007;115:e69-e171. doi:10.1161/ CIRCULATIONAHA.106.179918

151. Ojeda NB, Grigore D, Robertson EB, Alexander BT. Estrogen protects against increased blood pressure in postpubertal female growth restricted offspring. Hypertension. 2007;50:679-685. doi:10.1161/HYPERTENSIONAHA.107.091785

152. Sokol RZ, Okuda H, Stanczyk FZ, Wolfe GW, Delaney JC, Chapin RE. Normative reproductive indices for male and female adult Sprague-Dawley rats. Contraception. 1999;59:203-207. doi:10.1016/S0010-7824(99)00017-7

153. Woods LL, Ingelfinger JR, Rasch R. Modest maternal protein restriction fails to program adult hypertension in female rats. Am J Physiol Regul Integr Comp Physiol. 2005;289:R1131R1136. doi:10.1152/ajpregu.00037.2003

154. Katkhuda R, Peterson ES, Roghair RD, Norris AW, Scholz TD, Segar JL. Sex-specific programming of hypertension in offspring of late-gestation diabetic rats. Pediatr Res. 2012;72:352-361. doi:10.1038/pr.2012.93

155. Tao H, Rui C, Zheng J, et al. Angiotensin II-mediated vascular changes in aged offspring rats exposed to perinatal nicotine. Peptides. 2013;44:111-119. doi:10.1016/j.peptides. 2013.02.019

156. Ojeda NB, Intapad S, Royals TP, et al. Hypersensitivity to acute ANG II in female growth-restricted offspring is exacerbated by ovariectomy. Am J Physiol Regulat Integrat Comparat Physiol. 2011;301:R1199-R1205. doi:10.1152/ajpregu.00219.2011

157. Reckelhoff JF. Gender differences in the regulation of blood pressure. Hypertension. 2001;37:1199-1208. doi:10.1161/01. HYP.37.5.1199

158. Reckelhoff JF, Zhang H, Granger JP. Testosterone exacerbates hypertension and reduces pressure-natriuresis in male spontaneously hypertensive rats. Hypertension. 1998;31:435-439. doi:10.1161/01.HYP.31.1.435

159. Ojeda NB, Royals TP, Black JT, Dasinger JH, Johnson JM, Alexander BT. Enhanced sensitivity to acute angiotensin II is testosterone dependent in adult male growth-restricted offspring. Am J Physiol Regulat Integrat Comparat Physiol. 2010;298: R1421-R1427. doi:10.1152/ajpregu.00096.2010

160. Servier Medical Art. Availabe from: smart.servier.com.

\section{Publish your work in this journal}

Integrated Blood Pressure Control is an international, peer-reviewed open-access journal focusing on the integrated approach to managing hypertension and risk reduction. Treating the patient and comorbidities together with diet and lifestyle modification and optimizing healthcare resources through a multidisciplinary team approach constitute key features of the journal. This journal is indexed on
American Chemical Society's Chemical Abstracts Service (CAS) The manuscript management system is completely online and includes a very quick and fair peer-review system, which is all easy to use. Visit http://www.dovepress.com/testimonials.php to read real quotes from published authors. 